\title{
E-learning Benchmarking Adoption: A Case Study of Sur University College
}

\author{
Saleem Issa Al Zoubi ${ }^{1}$ \\ Computing Technology and Control System Department \\ Irbid National University, Amman, Jordan
}

\author{
Ahmad Issa Alzoubi ${ }^{2}$ \\ Information Systems and Technology (IST) Sur University \\ College, Muscat, Sur
}

\begin{abstract}
As an integral tool nowadays, e-learning presents fresh paradigm in the fields of education and management. The effectiveness of e-learning in the improvement of learning and teaching method has been proven. Accordingly, there have been countless works carried out to gain comprehension on the adoption of e-learning particularly in terms of its use extent. Furthermore, a new model of e-learning Success based on McLean \& DeLone Information System Success (IS Success) and Diffusion of Innovation (DOI) and the effects of e-learning on student's performance are comprehensively highlighted. Appositely, e-learning benchmarking adoption among students is characterized and measured in this study with the integration of DOI with IS Success attributed with such adoption. In this quantitative study, data were gathered from the students enrolled in SUC. The results indicate that and the variables of relative advantage, complexity, system quality, information quality and service quality appear to have significant linkage to the adoption of e-learning as well as net benefit is significantly correlated with the adoption of e-learning. In regards to the used methods for examining the adoption of e-learning particularly, future studies could benefit from the use of quantitative and qualitative methods in combination.
\end{abstract}

Keywords-e-learning; DOI; IS success; net benefit; extent of usage; LMS; benchmarking; quality assurance

\section{INTRODUCTION}

The exponential evolution of Information Communication Technologies (ICT) and Internet are influencing the delivery of learning and teaching process as it offers an innovative paradigm for the domains education and management today. Elearning concept carries the most comprehensive meaning towards the notion of openness. In the context higher education, e-learning adoption is highly essential as it facilitates the significant transformation in the learning and teaching process. The verity of factors namely how students and instructors are supported in its use, the integration of technology within the student learning experience and the availability of technology are the most significant criteria for successful adoption and usage of e-learning within the entire organization $[1,2]$.

Learning style transformation has been facing challenges. Among these challenges are continuous development of users' technological skills and shifts in cultural expectations. These challenges cannot be neglected; they have to be addressed. Effectively implementation of e-learning is crucial as this will guarantee enrichment of users' experiences. For this reason, fitting usage of technological combination has to be assured as this will result in fruitful ICT application in the context of education. The usage of E-learning encompasses usage of ICT in various education domains, and such usage in the context of higher education institutions imparts user with learning quality. ICT technology usage as the conventional classrooms' addons, online learning or combination of both modes, are among such examples [3, 4].

E-learning has been proven to be beneficial. For instance, e-learning opens more doors to learners towards education at lower cost and not only that learner could also engage in learning at all times and venues. Besides that, geographical hindrance is solved with e-learning as the technology allows learner to gain access at their convenience and this capacity enhances the quality of education. Meanwhile, with e-learning, interactions between learners and teachers or between learners and learners are improved via the model of learning network model. Also, increase can also be seen on the level of IT literacy through e-learning, while decision making becomes faster $[5,6,7]$. For working people with interest in pursuing their studies, e-learning offers opportunities for part-time studies. In the past, part-time studies were not as available and those with interest would need to quit their job in order to attend classes. Comparatively, e-learning allows people to further their studies at select institutions while still working [8]. The presence of e-learning can be seen intertwined with the conventional learning. Not only that, e-learning has become the solution to the problems associated with the conventional learning.

In this globalization era, the significance of education in the improvement of government's human capital is recognized by governments including that of Oman. In Oman, e-learning is deemed important because it resolves the challenges presently obstructing learning in the country. Still, the adoption of elearning in this country is rather low, just in other developing countries. Countless social transformations have been faced by the Sultanate of Oman and such have changed the needs of the Omani society. The Internet, in addition to other types of eLearning platforms, has been integrated into the system of education in Oman. Such integration has compelled teachers and faculty members go online. Moodle, WebCT, and e-portals learning management systems are among those platforms utilized in educational institutions [9].

In the context of Oman, e-learning is quickly turning into a crucial component in the process of education in this country. E-learning is the next big thing after the printing press came into the scene. As Oman has swiftly expanding workforce 
consisting of graduates that are flexible and well educated, it could greatly contribute to e-Learning within the region. Being an ambitious project launched by the Ministry of Higher Education, e-learning system provides the best imaginable elearning solutions to both the students and staff. In Oman, elearning is developed and implemented to encourage lifelong learning and satisfy the demand for unremitting professional development in the country. In Oman and the neighbouring countries (Arab countries), e-learning is deemed as a novel learning and teaching approach.

Accordingly, this study will examine the extent of elearning adoption among undergraduates in Oman, particularly those enrolled in Sur University College (SUC). Further, the gathered information is compared with the benchmarking of elearning used by international education agencies. The benchmarking to use for SUC will also be proposed. Previous empirical studies that conducted on e-learning in Oman have examined the introduction, use and the potential impact of the ICT on learning. For example, a study conducted by [10] to investigate the barriers of e-learning adoption in higher education in Oman: academics' perspectives. [11] carried out a study on impact learning management system has done on students and how effectively LMS has influenced students on their academic activities. These studies did not explain further factors that might control e-learning adoption from the students' perception. In addition, there is no evidence of studies done on factors affecting adoption of e-learning in the context of Oman as well as integrated Rogers DOI with D\&M IS model. Thus, the Higher Education in Oman needs to have some guidelines to ensure the successful and efficient implementation of e-learning in higher learning institutions. In case of Oman as a developing country, till now, there is little published evidence on what is the extent of e-learning adoption.

The rest of this research is organized as follows. The next section provides a statement of the problem, significance of the study and scope of the study. Literature review related to the theories that explain diffusion of innovation and adoption will be argued. Section 3 will describe in detail the methodology adopted in this research. At the end, discussion on the results and conclusion is presented.

\section{A. Statement of the Problem}

Several problems and challenges have been frequently faced by students during their e-learning activities. Since elearning lacks face-to-face interaction between learner and instructor, students are obliged to have more independence and responsibility towards their own process of learning [12]. This may compel students to change their ways of thinking, behaviour and habits to succeed in their studies. However, as reported in [13] there are students who are showing disinterest in technology utilization. These students are more comfortable with the traditional learning mode (i.e., face-to-face interaction in physical classrooms). Moreover, reported the lack of knowledge, skills, training as well as the negative attitudes towards technology usage as the primary factors of students' resistance towards e-Learning usage in their education. Meanwhile, [14] emphasised the need for students to cultivate skills and confidence in e-Learning usage all through their education. In particular, there are few studies that have aimed to build a theoretical framework to examine e-learning adoption among learners. Thus, there is a need for a theoretical framework that can be used to solve many problems associated with e-learning adoption [15].

As generator of standard and reference point, benchmark is generally described as the criterion employed in measuring, scoring or judging something. As reported in [16] [8] for elearning, internationally established benchmarking is available. Still, in the context of Oman, benchmarking of e-learning is still far from perfect. However, among the benchmarking initiatives include benchmarking of virtual campuses in Europe and Chiron. This benchmarking is linked to the project on state-of-the-art technological solutions for ubiquitous learning. This study attempts to employ a set of indicators to benchmark e-learning in order to facilitate the examination of e-learning adoption in higher education institutions in Oman, and in this study in particular, in SUC.

In Oman, various programmes have been initiated by the government in promoting e-learning adoption. Nonetheless, only a handful of works were devoted to the characterization of e-learning adoption and the scrutiny of e-learning adoption behaviour in this country. In the context of developing countries, Oman included e-learning applications, particularly with respect to the adopted applications type and their usage denoting their patterns of adoption patterns need more exploration. Additionally, empirical studies presenting an innovative model of e-learning Success grounded upon IS success and DOI in addition to the effects of e-learning in both developing and developed countries, creating a gap, which this study will attempt to fill.

\section{B. Significance of the Study}

Studies that explore the use of e-Learning among students at Omani universities, as well as the skills of students towards e-learning application in their education are still too few. Accordingly, the significance of this study is factored by several reasons. Firstly, the accessible information to demonstrate e-learning adoption in accordance with the benchmarking set selected is still limited. In addition, there is prospective in taking upon benchmarking for the improvement of the content and delivery development, change management and IT planning for uptake of e-learning. Also, this study offers universities in Oman information pertaining to use of elearning usage, which will motivate additional works on students' knowledge regarding e-learning and their skills toward this tool in learning and teaching arena. Besides that, from this study, the presidents of universities could be imparted with future plans regarding their needs for computers and new comprehension and attitudes toward e-learning. Ultimately, this study presents a new model of e-learning Success following the IS Success Model and the Roger's DOI for the purpose of assisting education scholars in the application of elearning in their field which leads to more development in elearning utilization in higher education [8].

It is crucial to have clearer comprehension of the factors that positively or negatively impact the adoption of e-learning among students in order to assure success of the e-learning implementation itself [17]. For this reason, it is important that this study is conducted, in Oman particularly. 


\section{Scope of the Study}

E-learning comprises computer technology or ICT usage in giving instruction to students and in allowing them to complete their credit courses online. E-learning comes in countless of modes including video-conferencing, video, television, blended learning, just to name a few. In this study, e-learning adoption scope covers the application of web-enabled LMS for the purpose of improving the learning quality and flexibility to all undergraduates. In the context of SUR, its learning portal is known Moodle and all students of SUC can have access to it. Flexible and qualitative learning is offered by these learning portal applications to all students but for the purpose of this study, only undergraduate students will be the focal point.

\section{LITERATURE REVIEW}

\section{A. Definitions of Electronic-Learning}

Definitions for e-learning are various. Also, terms used in delineating e-learning vary, including online education, Learning Management System (LMS), web-based learning online learning, distance education, and distance learning [18, 19] but generally, e-learning is viewed as the application of information and communication technology (ICT) in education, computer support instruction, online education or computer-aided domains for the purpose of improving education $[20,21]$.

As described in [22] and [23] the modes of e-learning generally falls within two categories namely Asynchronous elearning and Synchronous e-learning. Asynchronous e-learning generally includes the use of media including e-mail and discussion boards, supports work interactions between learners and teachers even without the online presence of participants, whereas Synchronous e-learning usually includes the application of media including Videoconferencing and chat, which could support e-learners in establishing the communities of learning. According to learners and teachers, synchronous elearning is perceived to be more social, and as it allows realtime questioning and answering session, frustration can be prevented. Some institutions use both modes of e-learning (Asynchronous e-learning and Synchronous e-learning) particularly those offering courses of e-learning to their remote learners [22, 24].

In [25] e-learning is viewed as a mode of learning that allows the fastest possible information delivery to learner. In [26], e-learning is described as a learning mode that is supported by ICT and this learning mode enhances teaching and learning in terms of quality. Author in [27] views eLearning as the effective addition to supplement the conventional teaching and learning. As perceived by [28] eLearning is not bound by place; it can happen anywhere such as university halls, home, and work, just to name a few.

The term e-learning is a general one and it can describe the application of all electronic means in education domain. This learning mode was in fact dubbed as internet enabled learning in [29]. Somehow, considering that the focal point of this study is students, e-learning is therefore referred as the application of electronic media for the delivery of adaptable learning. In this context, e-learning will encompass access to, downloading and utilization of web, $\mathrm{CD}$ or computer learning resources either in classroom or at home. In addition, access to and partaking in course activities including group discourses and evaluation activities are also included. Furthermore, in the context of this study, e-learning is interchangeably referred as learning management system (LMS), and also as SUC Moodle.

\section{B. Theoretical and Models of Technology Acceptance}

Adoption and Diffusion of Innovation (DOI) theory was first introduced in the work of [30]. The purpose of this theory was to delineate the diffusion of innovation and adoption of novel technology. Accordingly, the term diffusion was defined by the author as the process whereby an innovation is conveyed among members of a social system via specified channels over time. An innovation comprises a fresh idea, object, or practice as perceived by the related adoption unit [31], and for an individual, the newness of the innovation, as he perceives, will dictate how he reacts towards it.

The attributes impacting the innovation adoption and diffusion namely relative advantage, compatibility, complexity, trialability and observability were also highlighted in [30]. In this regard, diffusion of innovations model by Rogers is deemed the most essential adoption and adaption model due to its appropriateness as a research framework while also the most commonly tested model among [32, 33, 34, 2, 15].

As e-learning is an innovative learning mode, innovation diffusion theory is appropriate for e-learning adoption researches $[35,4,2]$. The theory is also fitting in examining how the beliefs of potential adopters regarding the innovation characteristics affect the adoption of e-learning. In this regard, [36] mentioned [30] model as among the most significant models in delineating the characteristics of innovation.

Among the most commonly cited models of IS success is that of DeLone \& McLean [37, 38]. This implies the capacity of a systematic blend of specific measures from categories of IS success in generating an all-inclusive instrument of measurement. The DeLone and McLean model comprises 6 dimensions of IS success as follows: (1) system quality, (2) information quality, (3) use, (4) user satisfaction, (5) individual impact and (6) organizational impact.

In comprehending the success of IS, the use of the IS greatly contributes in two ways: offering a system for the categorization of variety of measures of IS success as reported the literature, and the recommendation of a model that illustrates the temporal and causal interdependencies between the categories [27, 15]. Several empirical works have been carried out since early 90s regarding the multidimensional connexions among IS success measures, for instance, [39, 2, 38,38 ] for instance, part of the model was tested and for the purpose, the authors employed structural equation model (SEM). Such study has expanded the model via the inclusion of new dimensions including intention to use, service quality, and Net benefits (as substitutes to the construct of organisation impact) [40]. Approximately $38 \%$ of research paper have used D\&M IS model [41, 42]. A total of 300 articles were used this model in the range of 1992 to 2003 [34, 43]. In between 1992 to 2014 the total of 3500 articles have used these models. This demonstrates how strong these models are, in information systems and e-learning systems and updated model in 
particular which is DeLone and McLean. The aim of this study is to integrate Rogers DOI with IS model for examining elearning adoption similar to the studies applied by [43, 15]. One theoretical model for evaluating e-learning adoption successfully is not sufficient [44]. Due to, Rogers DOI and IS model have emerged and each has been the basis for studies examining systems adoption. These two models streams have numerous parallels as suggested by $[45,39,15]$ and other researchers.

Briefly stated, this study primarily attempts to characterise and measure the adoption of e-learning amongst learner, and determine the factors impacting these learners' adoption of elearning. Notably, this study pioneers the development of a success model for e-Learning grounded upon DOI theory by Rogers and the IS success model proposed by Delone and McLean.

\section{Technology Factors}

Innovations carry attributes affecting the decision to adopt, implement and utilize the innovations [30]. Accordingly, [30] presented five characteristics of innovation that affect the attitude of individuals in the process of adoption, namely: relative advantage, compatibility, complexity, trialability, and observability. Each is elaborated as follows:

Relative advantage relates to the level to which an innovation is viewed to be superior as compared to the notion it succeeds. Compatibility relates to the level to which an innovation is viewed to have consistency with the values at present time and experiences in the past. Meanwhile, complexity relates to the level to which an innovation is viewed to be challenging in comprehension and utilization, whereas trialability relates to the level to which an innovation may be trialled. As for observability, it is associated with the level to which the outcomes of an innovation are noticeable to others.

In analysing innovation characteristics proposed by Rogers across a vast range of types of innovation, [46] reported compatibility, relative advantage, and complexity as having the significant linkage to adoption. Accordingly, this study will employ 3 innovations characteristics of e-learning adoption among learners, namely relative advantages, compatibility and complexity (e.g., [47, 46]) with the aim of integrating the innovation characteristics that Rogers had proposed namely compatibility, relative advantage, and complexity, alongside the Delone and McLean IS success model which comprises information quality, system quality and service quality, in order to evaluate the adoption of e-learning. System quality relates to the perceived ease of use of system and it measures by adaptability, availability, reliability, response time and usability [40]. The significance of system quality on adoption intention has been highlighted in [43] in their discussion on Internet usage. Information quality relates to the degree to which users are confident that the information is timely, complete, accurate, and has relevance [48]. The service quality of the support received by system users is provided by the IS department and IT support personnel, and it encompasses the following: responsiveness, accuracy, reliability, technical competence, and empathy of the personnel staff. Indeed, information quality demonstrates the content attributes that a message carries. System quality, service quality, and information quality that impact the adoption and usage of elearning among users must be understood in order to achieve better e-learning adoption and implementation $[49,50]$.

Both the innovation characteristics by Rogers and Delone and McLean IS success model underpin this study's investigation of systems adoption. The past works on both appear to be comparable to one another $[42,51]$. For instance, DOI theory by Rogers stipulates that the effort made by an organization toward the diffusion of suitable IT inside a user community is comparable to Delone and McLean IS success model [52]. Accordingly, there are 6 factors proposed in the measurement of e-learning adoption among learners as follows: compatibility, relative advantage, complexity, information quality, system quality and service quality. The ensuing section will present the steps involved in the Delone and McLean IS success model.

\section{The Outcome of e-Learning on Students}

Author in [40] added the dimension of system impact or net benefit in examining the result of a given Information System evaluation. Pertinently, [53] proposed moving in reverse direction and assembling all measures of impact into a class of singular impact or benefit which they refer as "net benefits" (NB). As presumed in past work, system impact or NB is appropriate in all settings of education. NB denotes the manner in which the system can bring benefit to individual user, a group of users, an organization or the industry in its entirety. NB has linkage to job performance of users and also to the change in work activity and enhanced productivity. Hence, evaluation can be made to Net Benefits of individuals via job effects, efficiency, error reduction, decision quality, as well as effectiveness [40,13]. Meanwhile, in the evaluation of learning management system (LMS), net benefits highlight the balance of positive and negative effects on the behavior of users, and this involves system developers, instructor and learner, administrator, or all of the stakeholders of distance learning.

\section{METHODOLOGY}

This quantitative study employs survey questionnaires which were manually distributed to respondents. For this study, the determined population encompasses degree students enrolled in SUC. Accordingly, a sample frame which encompasses a list of population elements from which a sample can be drawn was attained from SUC Students. Meanwhile, the identification of respondents was performed using the approach of random sampling. This study received assistance from the representatives of several student residential halls in identifying the respondents. Respondents were given two weeks to complete and return the questionnaires.

\section{A. Questionnaire Design}

There are three major components contained within this study's questionnaire. These include items for eliciting the demographic information of the respondents as well as those that provide indications in benchmarking the uptake of elearning. For e-learning Benchmarking adoption, the respective items were obtained from SUC E-learning Moodle. There are two menus: Main Menu and Course Menu. Through adoption 
and usage, the framework measures e-learning adoption, and the measures follow four-point ordinal measures. The measurement scale which denotes the respondent's volume and sophistication of usage ranges from 'Not Using' to 'Use all the time.' These measures present the benchmarking for the adoption of LMS. The final section is to identify the factors impacting the e-learning adoption benchmarking while also measuring the effect of learner's e-learning adoption.

\section{FINDINGS}

\section{A. e-Learning Adoption and Identifying Adoption Groups}

The application of the framework in characterizing and measuring SUC students' e-learning adoption is discussed in this section. In this study, the respondents were asked to identify the types of e-learning applications that they were using and for each application, they were using, they were asked to determine the extent of usage. The adoption level provided denotes the present state of e-learning applications used by respondents, in this context, the students, and it also addresses the questions regarding the usage of these applications among students.

\section{B. Level of Adoption}

The adoption level describes the present state of e-learning applications that the students were adopting and it presents an initial depiction regarding the types of applications that Omani students were using. Accordingly, the e-learning applications distributions of these students can be viewed in Fig. 1. As shown by the figure, online registration appears to be the most popularly adopted among students at $96.7 \%$, followed by online grades at 96.2. Meanwhile, online save documents were adopted most by $90.7 \%$ of learners, while attaching was adopted by $86.1 \%$ of learners, whereas $78.1 \%$ learners have adopted online search. With respect to online courses material, it was adopted by $71.6 \%$ of learners. Assessment and Mic.word were adopted by about half $(50.2 \%)$ of the learners. The use of Email, online library, excel, powerpoint, PDF and electronic journals was in the range of $44 \%$ to $3.8 \%$ of the respondents. Four applications were not used as follows: chat room, video or audio, discussion group, and testing.

\section{Extent of Usage}

The use extent illustrates on the present situation of elearning application among learners. The four categories (not using, used sometime, used most of the time, and used all the time) were used to determine the usage level of adoption of elearning $[8,2]$. It also addresses the questions regarding the usage of these applications among students.

As Fig. 2 is showing, none of the students used video or audio, discussion group, testing, or chat room. On the other hand, $37.7 \%$ of students who was adopted assessment and Mic. Word stated that they used the applications sometime, whereas $12 \%$ of them stated that they used both applications most of the time, and just 5\% stated that both applications were used all the time. Less than half (45\%) of the students had never used both applications. Registration and grades were used 'sometime' by $27.8 \%$ of students, and were used 'most of the time' by $38 \%$ of the students. These applications were used 'all the time' by $30 \%$ of the students, and only $3.2 \%$ of the students stated that they never used them.

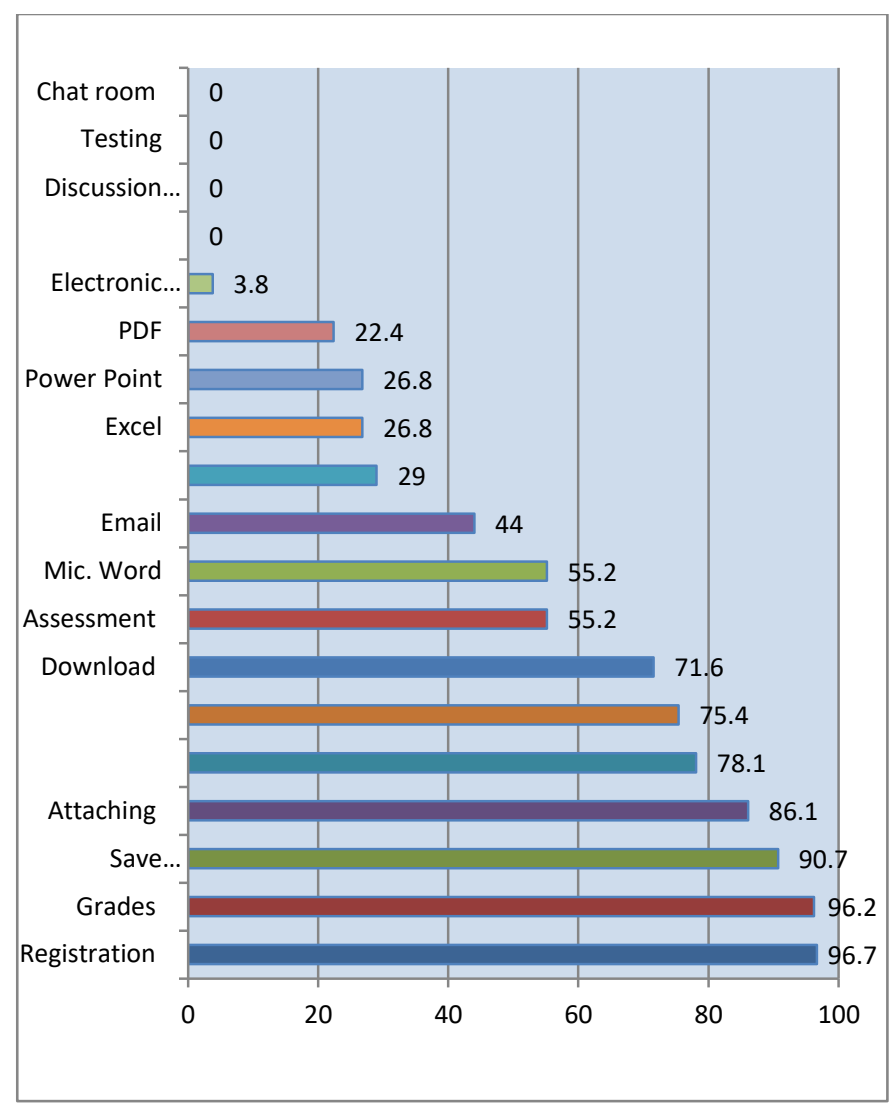

Fig. 1. Level of Adoption.

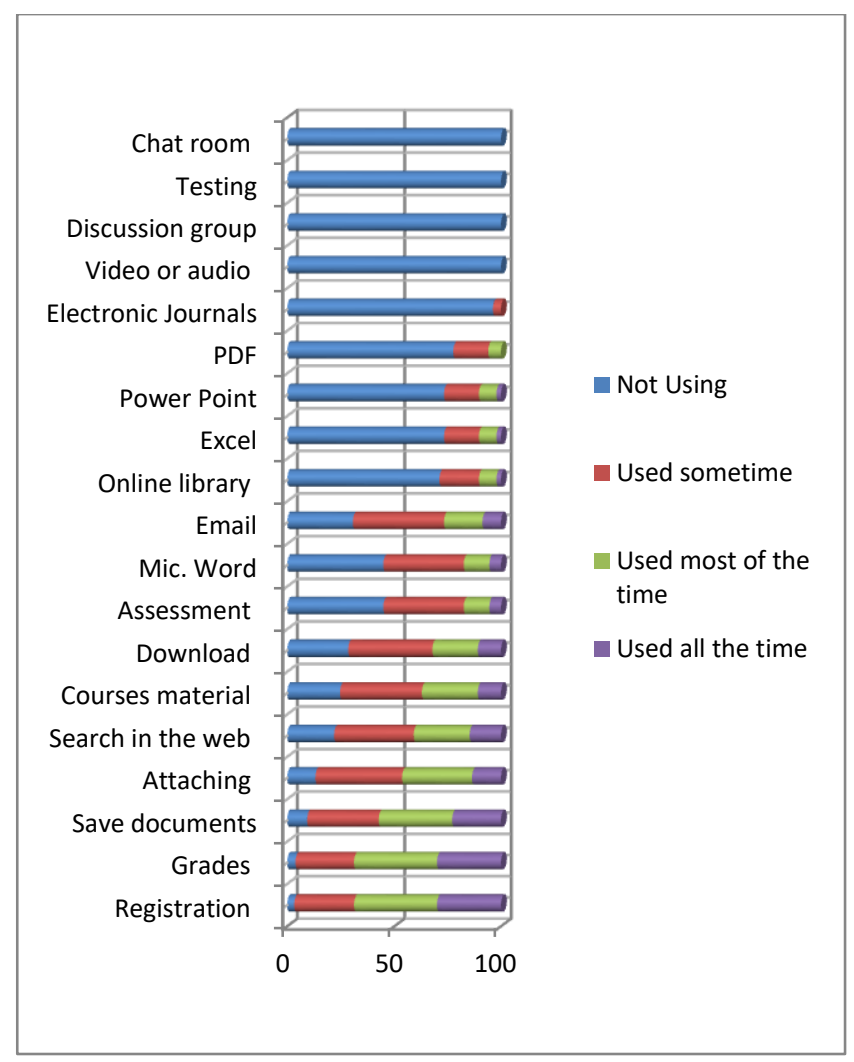

Fig. 2. Extent of usage. 
Electronic journals were used 'most of the time' by $3.8 \%$ of the students while the majority of student $(96.1 \%)$ stated nonusage of this application. Online library was not used by a large majority of students at $71 \%$, while only $2.1 \%$ of the students stated that they used this application all the time, whereas approximately $8.1 \%$ stated that they used this most of the time. Further, online library was used 'sometimes' by $18.1 \%$ of the students. About $30.6 \%$ of students stated that they had never adopted the use of email while $18 \%$ expressed that they used it most of the time. Meanwhile, $8 \%$ used email all the time and $42.6 \%$ used this application sometimes.

With respect to the use of Search in the web, roughly $21.8 \%$ of students stated non-usage of it, while $26 \%$ stated that they used this application most of the time, whereas $14.7 \%$ indicated usage of the application all the time. About $37.1 \%$ of students stated that they used this application sometimes. In terms of the application of Save documents, $34.4 \%$ of students stated usage of 'most of the time', while $22.9 \%$ stated usage of 'all the time' whereas $33.3 \%$ stated usage of 'sometimes.' Those that never used this application accounted for $9.2 \%$. The application of Attaching was used 'most of the time' by $32.7 \%$ of the students, 'all time' by $13.6 \%$ of students, and 'sometimes' by $40.4 \%$ of students. Attaching application was never used by $13.1 \%$ of the students.

The applications of Excel and PowerPoint were never used by $73 \%$ of the students, while the remaining $27 \%$ is represented by usage of 'sometimes,' 'most of the time' and 'all the time' in combination. Online Courses material was used 'sometimes' by $38.2 \%$ of students, 'most of the time' by $26.2 \%$ of students, and 'all the time' by $10.9 \%$ of students. Those who never used this application accounted for $24.5 \%$. Download was used 'most of the time' by $21.3 \%$ of students, 'all the time' by $10.9 \%$ of students, and 'sometimes' by $39.3 \%$ of students. On the other hand, $28.4 \%$ stated non-usage of this application. Non-usage of PDF was expressed by most students $(77.5 \%)$, while $16.3 \%$ stated that they used this application sometimes, and PDF was used most of the time by $6 \%$ of students.

The outcomes indicate that the applications of Assessment, Attaching, Chat room, Courses material, Discussion group, Download, Electronic Journals, Email, Excel, Grades, Mic. Word, Online library, PDF, PowerPoint, Registration, Save documents, Search in the web, Testing, and Video or audio were used 'sometimes' by the majority of the students. Also, among these applications, Registration and Grades were used the most while live audio and live video showed the lowest level of usage.

\section{Identifying Adoption Groups}

The approach used in this study demonstrates the effectiveness in identifying the patterns of adoption present in the sample, and accordingly, students were grouped in accordance with the patterns of adoption. Consequently, Table I highlights the cluster members and the finalised three adoption groups obtained from the matrix table. These groups encompass low-adopters represented by $63.9 \%$ of students, moderate-adopters represented by $36 \%$ of students, and highadopters represented by $10.9 \%$ of students.
TABLE. I. DERIVATION OF FinAL GROUPS AND CLUSTER MEMBERS

\begin{tabular}{|l|l|l|}
\hline Group No & Preliminary Group & Final Group \\
\hline 1 & 76 & 117 (Low-adopters) \\
\hline 2 & $41\}$ & \\
\hline & \multicolumn{2}{|l|}{} \\
\hline 3 & 37 & 66 (Moderate-adopters) \\
\hline 4 & $29 \quad 1$ & $\begin{array}{l}20 \text { (High Moderate - } \\
\text { adopters) }\end{array}$ \\
\hline & 20 & \\
\hline 5 & 183 & 183 \\
\hline & \multicolumn{2}{|l}{} \\
\hline Total & \multicolumn{2}{|l}{} \\
\hline
\end{tabular}

\section{E. Research Conceptual Framework Evaluation}

Table II presents the summarized results obtained from the multinomial logistics regressions. This table highlights 6 predictor variables, and the variables of relative advantage, complexity, system quality, information quality and service quality appear to have significant linkage to the adoption of elearning.

As shown by the results, there are three groups of distinctive adopters namely low, moderate and high adopters. Also, the dimensions of relative advantage, complexity, system quality, information quality and service quality positively affect the probability of e-learning adoption in the context of low-adopters vs. high adopters and moderate-adopters vs. lowadopters as opposed to moderate-adopters vs. high adopters. In addition, the dimensions of relative advantage, complexity, system quality, information quality and service quality have significant linkage to e-learning adoption amongst students. These outcomes are in agreement with those of past works particularly with respect to the significance of the dimensions of relative advantage, complexity, system quality, information quality and service quality on students' adoption of e-learning.

TABLE. II. MULTINOMIAL LOGISTIC REGRESSION

\begin{tabular}{|c|c|c|c|c|c|c|}
\hline & \multicolumn{2}{|c|}{$\begin{array}{l}\text { Low-adopters } \\
\text { vs. } \\
\text { High- } \\
\text { adopters }\end{array}$} & \multicolumn{2}{|c|}{$\begin{array}{l}\text { Moderate-adopters } \\
\text { vs. } \\
\text { High-adopters }\end{array}$} & \multicolumn{2}{|c|}{$\begin{array}{l}\text { Moderate-adopters } \\
\text { vs. } \\
\text { Low-adopters }\end{array}$} \\
\hline & $\begin{array}{l}\text { Coff } \\
(\beta)\end{array}$ & $\begin{array}{l}\text { Wald } \\
\text { p- } \\
\text { value }\end{array}$ & $\begin{array}{l}\text { Coff } \\
(\beta)\end{array}$ & $\begin{array}{l}\text { Wald } \\
\text { p-value }\end{array}$ & $\begin{array}{l}\text { Coff } \\
(\beta)\end{array}$ & $\begin{array}{l}\text { Wald } \\
\text { p-value }\end{array}$ \\
\hline $\begin{array}{l}\text { Relative } \\
\text { Advantage }\end{array}$ & .601 & .011 & 5.884 & .281 & 3.710 & .413 \\
\hline Compatibility & .291 & .188 & .236 & .656 & .364 & .169 \\
\hline Complexity & .743 & .015 & .092 & .525 & .477 & .000 \\
\hline System Quality & .339 & .041 & .125 & .562 & .171 & .416 \\
\hline $\begin{array}{l}\text { Information } \\
\text { Quality }\end{array}$ & .688 & .021 & .482 & .482 & .134 & .033 \\
\hline Service Quality & .013 & .969 & .528 & .236 & .161 & .005 \\
\hline
\end{tabular}




\section{F. Outcome of E-Learning on Students}

The analysis of correlation was carried out in this paper to ascertain if the degree of e-learning adoption and the impact measure are related. As can be seen in Table III, net benefit is significantly correlated with the adoption of e-learning, with the positive correlation of $.196 * *$.

TABLE. III. E-LEARNING ADOPTION AND NET BENEFITS MEASURES

\begin{tabular}{|l|l|l|}
\hline \multirow{2}{*}{ EL Adoption Impact } & \multicolumn{2}{|l|}{ Job Performance } \\
\cline { 2 - 3 } & Sig. & $\mathrm{R}$ \\
\hline Adoption & $.196^{* *}$ & .000 \\
\hline
\end{tabular}

\section{CONCLUSION}

This research mainly contributes to the theoretical knowledge particularly with respect to innovation adoption and IS success theory. The research proposes a new model that describes a concrete set of factors that higher education policy makers and universities' managers have to concern about to facilitate learners to adopt and use e-learning in their teaching and learning process. The importance of the theoretical framework is to help the decision and policy makers to determine which factors need support and which need treatment to encourage the learners to adopt e-learning. This paper presented an e-learning adoption framework which is an alternative framework which elucidates innovation adoption. This involves two dimensions namely the level of the adopted e-learning application and the usage degree of each e-learning application. The scrutiny of the usage degree generated three adoption groups which also have linkage to factors relating to technology and e-learning outcome. At the individual-level of innovation adoption, the proposed framework presents a more expansive comprehension and more universal sense for innovation adoption. For this reason, the framework is applicable in the adoption of different IS/IT innovations or the e-learning system adoption within diverse industries. In the context of IS innovation adoption, the framework proposed in this study contributes in the adoption level as it presents information regarding the types adopted application, as well as the usage degree of each e-learning application as opposed to the utilization of a single perspective (adopted or not adopted). In addition, this framework improves DOI theory through the inclusion of factors of system quality, information quality and service quality alongside the outcome of e-learning contexts to the theory. Within the domain of innovation diffusion, a conceptual framework was theoretically established and empirically assessed using factors of technology and the outcome of e-learning which allows the evaluation of the use and outcome of e-learning among students. On the other hand, this study is a valuable addition to the Arab world as it presents information regarding e-learning adoption; it also offers fresh information for other comparable developing countries. Perusing this study, researchers could also carry out additional works on e-learning in the context of higher education students.

In terms of limitations of the study, the study had come across are worthy of mention as well. In fact, this study's strong point lies in the recognition of its limitations, as these limitations can pave new way for future works while also providing clarification to the theoretical implications. The merit of this study lies in its scrutiny on the quintessence of elearning adoption among Omani students, and considering that e-learning implementation in Omani academia is still rudimentary, there should be more studies done in this context. Hence, for future works on e-learning adoption, the use of other groups of students or participants is recommended as this may generate new significant findings. Apart from the use of other groups of students or participants, the scrutiny of other factors is also recommended in order to solve the issues of responsiveness and personalization.

\section{ACKNOWLEDGMENT}

The authors wish to acknowledge Irbid National University support, that without which this report would not have been accomplished.

\section{REFERENCES}

[1] T. Anderson and T. Elloumi, "The Theory and Practice of Online Learning," Edmonton: AU Press, 2011.

[2] S. I. Alzoubi and A. I. Alzoubi, "Investigating the Extent of Learning Management System Adoption in a Jordanian," International Journal of Business and Social Science, vol. 8, no. 1, pp. 208-216, 2017.

[3] OECD, " (2005) E-learning in tertiary education. [Online]..pdf (Accessed 21st April 2011).," 2005. [Online]. Available: Available at http://www.cumex.org.mx/archivos/ACERVO/ElearningPolicybriefenglis h. [Accessed 21 April 2018].

[4] A. Al-adwan and J. Smedley, "Implementing e-learning in the Jordanian Higher Education System: Factors affecting impact.," International Journal of Education and Development using Information and Communication Technology, vol. 1, no. 8, pp. 121-135, 2012.

[5] S. Alexander, "E-learning Developments and Experiences.," Education and Training, vol. 43, no. 4, pp. 240-248, 2001.

[6] M. Y. Cheng, "Antecedents and consequences of e-learning acceptance," Inf. Syst. J, vol. 21, no. 1, p. 269-299, 2011.

[7] J. L. Chen, "The effects of education compatibility and technological expectancy on e-learning acceptance," Comput. Educ, vol. 57, no. 1, 2011.

[8] S. L. Thi, M. N. Sharif, A. Darus and T. S. Lai, "Evaluating E-Learning Uptake in a Malaysian Higher Education Institution," International Conference on Information Systems for Business Competitiveness, pp. 1$8,2015$.

[9] R. Boateng, A. S. Mbrokoh, B. Lovia, P. K. Senyo and E. Ansong, "Determinants of e-learning adoption among students of developing countries," The International Journal of Information and Learning, vol. 44, no. 4, pp. 248 - 262, 2016.

[10] W. A. A. Rakhyoot, "Institutional and individual barriers of e-learning adoption in higher education in Oman : academics' perspectives," ETHOS, vol. 8, 2017.

[11] N. Sarachandran and R. Patil, "A Study on the Impact of Learning Management Systems on Students of a University College in Sultanate of Oman," International Journal of Computer Science Issues, vol. 9, no. 1, 2012.

[12] M. Hatcher and M. Yen, "Using theory of constraints in E-learning for overcoming internalexternal, cultural, and international constraints," Journal of the Academy of Business and Economics, vol. 5, no. 3, pp. 611-617, 2005.

[13] Ishtaiwa, "Factors influencing faculty participation in e-learning: the case of Jordan," AGFDS, vol. 2, no. 2, pp. 12-25, 2006.

[14] A. Macpherson, M. Elliot, I. Harris and G. Homan, "E-learning: Reflections and evaluation of corporate programs," Human Resource Development International, vol. 7, no. 3, pp. 295-313, 2004.

[15] I. S. Alzoubi and I. A. Alzoubi, "An Investigation of Factors affecting EMarketing Customers' Behavioral intention to use Telecommunication industry in Jordan; Vol. 11, No. 3, Published by International Journal of Marketing Studies.," 2019. 
[16] E. Ossiannilsson, "Benchmarking E-Learning inHigher Education," Lessons Learned from International Project. Unpublished Ph. D. Dissertation, University of Oulu, Finland, 2012.

[17] R. G. Saadé and D. Kira, "Computer anxiety in e-learning: the effect of computer self-efficacy," Journal of Information Technology Education, pp. 177-191, 2009.

[18] J. Hayen, J. Cappel and L. Roger, "Evaluating E-Learning: A Case Study," Ournal of Computer Information Systems, vol. 44, pp. 49-56, 2004.

[19] L. A. Halawi, S. Pires and Mccarthy, "An Evaluation of E-Learning on the Basisof Bloom's Taxonomy: An Exploratory Study," Education for Business, vol. 84, no. 6, pp. 374-380, 2009.

[20] S. M. Mutula, "E-Learning Initiative at the University of Botswana: Challenges and Opportunities," Campus-Wide Information Systems, pp. 99-109, 2002.

[21] C. Fallon and S. Brown, "E-learning Standards: A Guide to Purchasing," Developing, and Deploying Standards-Conformant E-Learning Press.: Delray Beach, , 2003.

[22] Moore, Deane and Galyen, "e-Learning, online learning, and distance learning environments: Are they the same?," Internet and Higher Education, no. 14, p. 129-135, 2011.

[23] I. A. Al-Zoubi and Mohamad, "An Integrated Success Adoption Model for Examining E-Learning Among Adult Workers in Jordan. 978-1-47990059-6/13/31.00 @2014 IEEE".

[24] K. Behling, J. Orczyk and J. Jenkins, "Live distance learning delivery of Master of Science courses in building construction management," 37th ASEE/IEEE Frontiers in Education Conference, 2007.

[25] B. H. Khan, "Managing e-learning: Design, delivery, implementation and evaluation," pp. Hershey, PA: Information Science Publishing, 2005.

[26] Begičević, Divjak and Hunjak, "Imaginative acquisition of knowledge strategic planning of e-learning," ITI, pp. Cavtat, Croatia, 2006.

[27] M. McPherson and M. B. Nunes, "Organizational Issues for ELearning: Critical Success Factors as Identified by HE Practitioners," International Journal of Educational Management, vol. 20, no. 1, p. 542 - 558, 2002.

[28] P. Hadjiathanasiou, "The e-Learning readiness of Cyprus primary teachers ahead of dias system integration into Cyprus schools," European Journal of Open, Distance and E-Learning, pp. 34-51, 2009.

[29] A. Gunasekaran, R. D. McNeil and D. Shaul, "E-learning research and application.," Industrial and Commercial Training, vol. 32, no. 3, pp. 4453, 2002.

[30] E. M. Rogers, Diffusion of innovations, New York: The Free Press. (Original publication 1962), 1995.

[31] G. Zaltman, R. Duncan and J. Holbek, Innovations and organizations, vol. 1973, New York: Wiley , 1973.

[32] J. F. Enge, R. D. Blackwell and P. W. Miniard, Consumer Behaviour, 8th Ed, Chicago: Dryden Press, 1995.

[33] G. Salter and S. Hansen, "Facilitating web-based staff development in higher education In L Richardson \& J. Kidstone (Eds.)," ASET/HERDSA 2000 Flexible Learning for a Flexible Society, 2-5 July 2000, pp. 612617,2001

[34] A. I. Al Zoubib and Z. Jali, "An integrated success adoption model for examining E-learning among adult workers in Jordan," in International Conference on Computer and Information Sciences (ICCOINS), 2014.

[35] Y. a. Duan, "A study on e-learning takeup intention from an innovation adoption perspective: A case in Chin," Computers \& Education, vol. 55, pp. 237-246., 2010.
[36] G. C. Moore and I. Benbasat, "Development of an Instrument to Measure the Perceptions of Adopting an Information Technology Innovation," Information System Research, pp. 192-222, 1991.

[37] D. X. Ding, P. H. Hu and O. R. Sheng, "e-SELFQUAL: A scale for measuring online self-service quality," Journal of Business Research, Article in Press, 2010.

[38] H. H. Chang, Y. H. Wang and W. Y. Yang, "The impact of e-service quality, customer satisfaction and loyalty on e-mrketing: moderating effect of perceived value," Total Quality Management, vol. 20, no. 4, pp. 423-443, 2009.

[39] S. Alaa, "Digital storytelling: a meaningful technology-integrated approach for engaged student learning," Education Tech Research Dev, p. 487-506, 2008.

[40] W. H. DeLone and E. R. McLean, "The Delone and Mclean model of information systems success: A ten-year update," Journal of Management Information Systems, vol. 19, no. 4, p. 9-30, 2003.

[41] E. L. Lwoga, "Critical success factors for adoption of web-based learning management systems in Tanzania", International Journal of Education and Development using Information and Communication Technology, Vol.10, No.1,2014, pp.4-21."

[42] A. Ozkan and R. Koseler, "Multi-dimensional Students' Evaluation of Elearning Systems in the Higher Education Context: An Empirical Investigation", Computers \& Education, Vol.53, No.4, pp.1285-1296.," 2009

[43] C. J. Lin and C. Lu, "Towards an understanding of the behavioural intention to use a web site," International Journal of Information Management, vol. 20, pp. 197-208, 2000.

[44] S. H. Liu, H. L. Liao and J. A. Pratt, "Impact of Media Richness and Flow on E-Learning Technology Acceptance. Computers \& Education, 52(3), 599-607," 2009.

[45] M. B. Prescott and S. A. Conger, " Information technology innovations: a classification by IT locus of impact and research approach," The Data Base for Advances in Information Systems, p. 20-41, 1995.

[46] L. G. Tornatzky and R. G. Klein, "Innovation characteristics and innovation adoption-implementation: A meta-analysis of findings",," in IEEE Transactions on Engineering Management EM-29: , 1982.

[47] B. Chokri, "Factors influencing the adoption of the e-learning technology in teaching and learning by students of a University class," European Scientific Journal, vol. 28, no. 8, p. 1165-1190, 2012.

[48] Y. W. Lee, D. M. Strong, B. K. Kahn and Wan, "AIMQ: a methodology for information quality assessment," Information \& Management, p. 133146, 2002.

[49] S. Alkhalaf, S. Drew, R. AlGhamdi and O. Alfarraj, "E-Learning system on higher education institutions in KSA: attitudes and perceptions of faculty members," Procedia - Social and Behavioral Sciences, p. 1199 $1205,2012$.

[50] T. Ramayah and J. C. Lee, "System characteristics, satisfaction and elearning usage: A structural equation model (SEM)," TOJET: The Turkish Online Journal of Educational Technology, vol. 11, no. 2, pp. 2628, 2012.

[51] R. G. Fichman, "Going Beyond the Dominant Paradigm for IT Innovation Research: Emerging Concepts and Methods," Journal of the Association for Information Systems, pp. 314-355, 2004.

[52] R. B. Cooper and R. W. Zmud, "Information Technology Implementation Research: A Technological Diffusion Approach," Management Science, vol. 36, no. 2, p. 123-139, 1990.

[53] W. H. DeLone and E. R. McLean, "Information system success: the quest for the dependent variable," Information System Research, vol. 3, no. 1, pp. 60-95, 1992. 